\title{
Public Participation of Men Who Have Sex with Men in the Context of Community Empowerment in India
}

\section{Karikalan Nagarajan ${ }^{2}$, Seema Sahay ${ }^{1 *}$, Deepika Ganju ${ }^{3}$ and Ramesh S Paranjape ${ }^{2}$}

${ }^{1}$ National AIDS Research Institute (ICMR), Pune, India

${ }^{2}$ Formerly associated with National AIDS Research Institute (ICMR), Pune, India

${ }^{3}$ Population Council, New Delhi, India

\begin{abstract}
Background: Men who have sex with men (MSM) remain a hidden and hard-to-reach high-risk group. MSM experience stigma, discrimination and criminalization in India. The organized participation of MSM in "public spaces" --through which they openly identify themselves as MSM, address social stigma, and demand their rights and entitlements-- is an indicator of their empowerment process against structural barriers. This paper assesses MSMs' "public participation" and the contextual factors that influence them.
\end{abstract}

Method: Data were drawn from a cross-sectional Integrated Behavioral and Biological Assessment survey conducted during 2009-2010 in Tamil Nadu, India. Information was collected on the socio-demographic characteristics, public participation, community mobilization, vulnerability and risk status of $1757 \mathrm{MSM}$. Two set of measures thought to influence MSMs' public participation were considered "push" factors and "pull "factors. Pull factors were related to MSMs' community mobilization status and push factors were related to MSMs' risk and vulnerability.

Results: Almost half of the MSM (48\%) reported public participation in the past six months. Univariate and Multiple regression analysis shows that pull factors [exposure to peer education (OR 8.2 (4.0-16.6); AOR-6.1(1.9-19.4); $\mathrm{p}<0.05)$, collective membership (OR 10.2 (6.4-16.3); AOR 9.7 Cl 5.9-15.9; $P<0.05$ ) and collective agency (OR 3.2 (2.0-5.2); AOR 4.3 (2.3-8.1 P<0.05)] influence MSMs' likelihood of participating in public spaces. Experience of police arrest was a push factor that influenced MSMs' likelihood of participating in public places (AOR-3.7 Cl 1.6-8.4 P<0.05).

Conclusion: The community mobilization strategy is effective in fostering MSMs' "public participation;" through this strategy MSM can address structural barriers and the program can be upscale. Public participation of MSM can serve as a key indicator of the empowerment process in a stigmatized society.

Keywords: MSM; India; Stigma; Participation; Public spaces; Community mobilization; Empowerment

\section{Introduction}

HIV epidemic in India is a major public health concern, featuring high prevalence and infection rates in many states and among high risk groups (HRGs) [1]. Men who have sex with men (MSM) are a high-risk group (HRG) noted for high HIV prevalence and risk status globally and in India [2-4]. MSM in India remain largely hidden due to social and cultural stigma [5-8] and the stigmatizing socio-cultural environment, hinders them from accessing essential preventive services from existing social spaces $[9,10]$. MSM population has been prioritized under the National AIDS Control Programme but this population remains hard to reach due to high stigmatization, social stigma, and discrimination prevailing in the Indian society. In addition, criminalization of MSM activity by the Indian penal code under section 377 adds to their societal vulnerability.

In this context of vulnerability, the "organized participation" of MSM in open public spaces, where they identify themselves as MSM without stigma or fear, could be a proxy factor of empowerment against structural barriers that criminalize and stigmatize them.

Studies have highlighted in general, the positive relation of HRG "participation", with their practice of preventive sexual behaviors [1113]. We assessed the MSM "public participation" in an empowerment context, through which they address structural barriers. Our study pertains to the MSM participation in "public" spaces which is a first of its kind in distinguishing and assessing the so far theoretically defined participations in the contexts of community mobilization [14].
The study used a well represented high risk population which was undergoing wider "community mobilization" process in India. Thus it provided the opportunity to quantitatively verify and assess the transforming nature of participation from a "utilitarian tool" to an "empowerment tool" in a community mobilization process, the factors of community mobilization which influences such participations and other contextual factors.

\section{Methodology}

\section{Study design, population and period}

Data for the study were drawn from the second round of Integrated Behavioral and Biological -Assessment (IBBA) survey conducted between 2009-2010 among MSM respondents in Tamil Nadu ( $n=1757)$.

\section{Sampling method and sample size}

The survey used a two stage cluster sampling design with time

*Corresponding author: Seema Sahay, Department of Social \& Behavioral Research Division, National AIDS Research Institute, Pune, India, Tel: 91-20-27331200; Fax: 91-20-27121071; E-mail: ssahay@nariindia.org, seemasahay@yahoo.com

Received September 08, 2015; Accepted October 13, 2015; Published October 19, 2015

Citation: Nagarajan K, Sahay S, Ganju D, Paranjape RS (2015) Public Participation of Men Who Have Sex with Men in the Context of Community Empowerment in India. J AIDS Clin Res 6: 509. doi:10.4172/2155-6113.1000509

Copyright: (c) 2015 Nagarajan K, et al. This is an open-access article distributed under the terms of the Creative Commons Attribution License, which permits unrestricted use, distribution, and reproduction in any medium, provided the original author and source are credited. 
location clusters as primary sampling units, except in East Godavari district of Andhra Pradesh, where fixed location clusters were additionally used. The primary sampling units were selected by systematic random sampling, by probability proportional to size. From the selected clusters, respondents were chosen through simple random sampling using their dress code as labels. Sample sizes were calculated on the basis of the following factors typically used in surveys with probability samples: 1) The expected baseline value of key behavioral indicators (e.g. consistent condom use with various partner types): $50 \%$; 2) Magnitude of change it is desired to be able to detect : $10-15 \%$; 3) Confidence level set at 0.05 , corresponding to $95 \%$ confidence in the observed estimates; 4 ) The beta level was set at 0.10 , corresponding to 90\% and 5) Design effect: 1.7 and 4) This adjusts for the use of sampling designs that are not simple random methods, e.g. cluster sampling [15].

\section{Eligibility criteria}

Men aged $\geq 18$ years who had anal sex with another man in exchange for cash/kind in the last one month were included in the study.

\section{Data collection procedure}

Face-to-face interviews were conducted by trained field workers in Tamil, the local language of the state, using a structured questionnaire that included questions on socio-demographic characteristics, self identity, public participation, community mobilization, vulnerability and risk perception.

\section{Ethics statement}

Approval for the study was taken from ethics committees of the participating institutes of Indian Council of Medical Research. All study participants were requested to provide informed written consent prior to participation in the study at the time and site of enrollment. Trained study staff read the consent form aloud to the participant in the language of preference. The informed consent process informed the participants about the study intent, procedures, risks, benefits, compensation, and their rights to not participate or to withdraw at any time, and contact information for the study PIs and the Ethics Committee (EC) Chairperson.

\section{Operational definitions}

Public participation: It was defined as an active role played by MSM openly expanding his consciousness and presence without hiding his identity in public spaces and actively influencing decisionmaking which impacts their life. Each respondent was asked a direct question: In the past six months have you participated in a public event (like gatherings, rallies) where you could be identified as a MSM? It was measured as a categorical variable with responses as 'Yes' or 'No'.

Self-identity: Based on reported self-identity, respondents were grouped as "kothis" (mainly practicing anal-receptive sex) and "nonkothis", i.e., panthis (who mainly practice anal-insertive sex), doubledeckers (practice both anal-receptive and anal-insertive sex), hijra (transgender), and bisexuals (in both homosexual and heterosexual relationships).

\section{Pull factors}

Two sets of contextual measures were used to assess MSMs' public participation. Measures related to community mobilization status were considered "pull factors" which attract MSM toward "public participatory" spaces. The "pull factors" act by creating supportive environments that provide advocacy and incentives for MSM, which encourage public participation along with community members. Pull factors encourage the MSM towards participation in public.

The following measures of Pull factors were used in this study:

Collective Identity: Defined as the shared sense of oneness developed among people with shared identity. Variable used: You feel a strong sense of unity with other MSM/male sex workers (MSW) with whom you do not have an acquaintance. It was measured as a categorical variable with responses as 'Yes' or 'No'

Collective agency: Defined as the choice, control, and power that marginalized groups have to act for themselves to claim their rights and to hold others accountable for these rights. Variable used: In the past one year have you negotiated or stood up against the following (police, madam, and broker, and landlord, local politician) in order to help a fellow sex worker? It was measured as a categorical variable with responses as 'Yes' or 'No'

Membership in a collective: Measured by asking respondents whether they were members of a community based organization in the past one year. It was measured as a categorical variable with responses as 'Yes' or 'No'

Exposure to peer education: Measured by asking respondents whether they had received sexually transmitted infection (STI)/HIV information from a peer educator in the past one year. It was measured as a categorical variable with responses as 'Yes' or 'No'

\section{Push factors}

Measures related to the vulnerability and risk status of MSM were considered "push factors," which serve as negative experiences of MSM, prompting them to participate in public spaces as a response to confronting vulnerabilities against structural barriers. Push factors are negative experiences of MSM which force them towards participation in public.

The following measures of Push factors were used in this study

HIV risk perception: This was measured based on respondents' reports of MSM whether they felt themselves to be at high risk of acquiring HIV infection or not. It was measured as a categorical variable with responses as 'Yes' or 'No' If 'yes', then the respondent was considered to have HIV risk perception if ' $\mathrm{No}$ ', the respondent was considered to have no HIV risk perception.

Experience of AIDS caused peer death/ HIV infection: Measured by asking respondents whether they know someone (who also knows them) who is infected with HIV, or AIDS, or has died of AIDS? It was measured as a categorical variable with responses as 'Yes' or 'No'

Experience of police arrest: Measured by asking whether respondents had ever been arrested by the police. It was measured as a categorical variable with responses as 'Yes' or 'No' .

Socio-economic vulnerability: This was measured by asking respondents whether they have currently borrowed money as debt from others? It was measured as a categorical variable with responses as 'Yes' or 'No'. If 'yes', it was considered as an indicator for socio economic vulnerability of MSM.

\section{Data analysis}

Descriptive statistics were used to assess level of public participation among participating MSMs . Chi-square tests were used to assess the significance of bivariate relationships between demographic 
characteristics and public participation. Univariate and multiple logistic regression models were used to identify factors influencing MSMs' public participation. The dependent variable was taken as public participation (coded as 1 if participated and coded as 0 if not). The "push" and "pull" factors were used as the independent variables. The regression model was adjusted for age, duration of sex work, marital status, occupation status, and self-identity of MSM. All the variables which were included in the univariate regression were also used in multivariate regression to check for consistency of results with and without adjustment for background variables. The independent variables included in the analysis were based on contextual relation they had with the dependent variables and also from references from relevant studies published in the same study context among FSWs(Karikalan N, et al., 2014). Adjusted odds ratios were calculated at a significance level of $<0.05$. All statistical analyses were done after adjusting for sampling differences by applying state sampling weights. STATA/SE version 12.0 was used for all analyses.

\section{Results}

Descriptive statistics show that nearly half $(48 \%(n=884)$ of the participants reported public participation in the past six months (data not shown in table). Bivariate analysis in Table 1 shows that duration of sexual exposure was a characteristic that significantly distinguished MSMs' public participation.

Univariate and multivariate regression results in Table 2 show that MSM who had an exposure to peer education ( OR 8.2 -CI 4.016.6, AOR 6.1-CI 1.9-19.4; $\mathrm{P}<0.05$ ) ; had collective membership ( OR 10.2 -CI 6.4-16.3, AOR 9.7-CI 5.9-15.9; $\mathrm{P}<0.05)$ and collective agency ( OR 3.2 -CI 2.0-5.2, AOR 4.3-CI 2.3-8.1; $\mathrm{P}<0.05$ ) were 3 to 10 times more likely to report public participation respectively. MSM who had been arrested by the police were over three times more likely to have participated publicly (AOR-3.7 CI 1.6-8.4; $\mathrm{P}<0.05$ ) than who MSM who were not arrested. MSM who experienced an AIDS caused peer death/ HIV infection were less likely to report public participation (OR 0.4 CI 0.3-0.7; AOR 0.4 CI 0.3-0.7; $<<0.05$ ) than MSM who had no such experience.

\section{Discussion}

This is first report from India that reveals that community mobilization factors act as potential "pull factors" in enabling public participation in the empowerment context of MSM in addition to influencing safe sexual behaviors.

Our assessment of MSMs' public participation is significant in Indian settings, where social stigma remains a key structural barrier for MSM, increasing their vulnerability. Public participation can be theoretically explained as participation with an "intrinsic value", through which marginalized communities seek a wider vision of societal empowerment. Other studies have noted two different rationales for participation in the context of HIV intervention: "considering participation as a means to a more effective intervention, and participation as a desirable end in itself" $[16,17]$. Here , public participation serves as desirable end in itself a tool for self- and social empowerment for vulnerable populations like MSM to increase their social capital, self-efficacy, ability to renegotiate social norms and health enhancing social support [18].

Results show that only half of the MSM in the study population of Tamil Nadu reported public participation, which indicates the marginalization experienced by the remaining 50 percent who remain hidden; hence vulnerable. MSM with a higher duration of sexual exposure were more likely to participate in public places, underlying the role of their years of experience as MSM in realizing their empowerment needs. Community mobilization indicators have been widely noted for influencing safe sex behaviors among HRGs in their sex settings. Multiple studies have noted that public visibility, collectivization and collective efficacy were associated with safe condom use among female sex workers and MSMs $[11,13,19,20]$.

While peer education has been generally stressed in the context of promoting individual safe behavior changes and awareness creation among HRGs in general [1,3,21]; this study shows that peer education has a positive impact on the empowerment efforts of MSM by influencing public participation, signifying that it is a principal

\begin{tabular}{|c|c|c|c|}
\hline \multicolumn{2}{|c|}{ Background characteristics } & \multicolumn{2}{c|}{ MSMs' public participation } \\
\hline & & $\begin{array}{c}\text { Yes (N=884) } \\
\mathrm{n}(\%)\end{array}$ & $\begin{array}{c}\text { No (N=871) } \\
\mathrm{n}(\%)\end{array}$ \\
\hline Age (years) & $>=25$ & $312(49.2)$ & $321(50.7)$ \\
\hline & $<25$ & $572(50.9)$ & $550(49.0$ \\
\hline $\begin{array}{c}\text { Duration of sexual } \\
\text { exposure (years) }\end{array}$ & & & \\
\hline & $0-5$ & $71(36.2)$ & $125(63.7)^{\star}$ \\
\hline & $5-10$ & $271(53.1)$ & $239(46.8)$ \\
\hline Married & $10-65$ & $542(51.6)$ & $507(48.3)$ \\
\hline Sex work occupation & & $212(49.4)$ & $217(50.5)$ \\
\hline Education status & $<=$ elementary & $133(47.0)$ & $150(53.0)$ \\
\hline & $>=h i g h$ school & $751(51.0)$ & $721(48.9)$ \\
\hline Self-identity as kothi & & $725(50.4)$ & $712(49.5)$ \\
\hline
\end{tabular}

${ }^{*} \mathrm{p}<0.05$ Chi Square

Table 1: MSMs' public participation by background characteristics in Tamil Nadu, India

\begin{tabular}{|c|c|c|c|c|}
\hline \multicolumn{2}{|c|}{ Contextual factors } & $\begin{array}{l}\text { MSMs who } \\
\text { reported public } \\
\text { participation } \\
(\mathrm{N}=884) \\
\mathrm{n}(\%)\end{array}$ & $\begin{array}{c}\text { Unadjusted } \\
\text { OR (CI) }\end{array}$ & $\begin{array}{c}\text { Adjusted OR } \\
\text { (Cl) }\end{array}$ \\
\hline \multicolumn{5}{|c|}{ Push factors (n) } \\
\hline \multirow[t]{2}{*}{ HIV risk perception } & Yes (637) & $361(42.3)$ & $1.6(1.0-2.5)^{*}$ & $1.0(0.6-1.6)$ \\
\hline & $\mathrm{No}(1118)$ & $523(57.7)$ & ref & ref \\
\hline \multirow{2}{*}{$\begin{array}{l}\text { Experience of AIDS } \\
\text { caused peer death }\end{array}$} & Yes(842) & $377(39.6)$ & $0.4(0.3-0.7)^{\star}$ & $0.4(0.3-0.7)^{*}$ \\
\hline & No(913) & $507(60.3)$ & ref & ref \\
\hline \multirow{2}{*}{$\begin{array}{l}\text { Experience of } \\
\text { police arrest }\end{array}$} & Yes(91) & $62(7.0)$ & $1.6(0.4-6.0)$ & $3.7(1.6-8.4)^{\star}$ \\
\hline & $\mathrm{No}(1664)$ & $822(92.9)$ & ref & ref \\
\hline \multirow{2}{*}{$\begin{array}{l}\text { Socio Economic } \\
\text { Vulnerability }\end{array}$} & Yes (826) & $409(54.9)$ & $1.4(0.9-2.2)$ & $1.3(0.8-2.0)$ \\
\hline & No (929) & $475(45)$ & ref & ref \\
\hline \multicolumn{5}{|c|}{ Pull factors } \\
\hline \multirow{2}{*}{$\begin{array}{l}\text { Exposure to peer } \\
\text { education }\end{array}$} & Yes (1561) & $862(97.8)$ & $8.2(4.0-16.6)^{*}$ & 6.1(1.9-19.4)* \\
\hline & No(194) & $22(2.1)$ & ref & ref \\
\hline \multirow{2}{*}{ Collective identity } & Yes(1589) & $853(94.7)$ & $3.5(1.8-7.0)^{\star}$ & $1.6(0.6-3.9)$ \\
\hline & No (166) & $31(5.2)$ & ref & ref \\
\hline \multirow{2}{*}{ Collective agency } & Yes (427) & $309(31 . .2)$ & $3.2(2.0-5.2)^{\star}$ & $4.3(2.3-8.1)^{*}$ \\
\hline & No (1328) & $575(68.8)$ & ref & ref \\
\hline \multirow{2}{*}{$\begin{array}{l}\text { Collective } \\
\text { membership }\end{array}$} & Yes (894) & $676(76.4)$ & $\begin{array}{c}10.2(6.4- \\
16.3)^{\star}\end{array}$ & $9.7(5.9-15.9)^{\star}$ \\
\hline & No (861) & $208(23.5)$ & ref & ref \\
\hline
\end{tabular}

* $p<0.05$; Model adjusted for age, duration of sex work, education status, marital status, occupation and self-identity

Table 2: Multivariate analysis of MSM public participation in Tamil Nadu, India 
component in community mobilization interventions [22]. The community mobilization intervention brings in confidence because it conforms to the theoretical postulates especially that of Health Belief Model (HBM) which shows that interpersonal and external social factors act together in an individual, for her/him to adopt a beneficial action [23]. Thus "peer education exposure," which influences MSMs" public participation, can be explained as a "cue of action", a theoretical construct of the HBM, which is defined as external events/persons that "triggers a person on the way to changing behavior" [24].

MSMs "experience of police arrest" was a push factor, another cue to action, that influenced their public participation in this study, which corroborates findings from studies of FSWs where police related violence was effectively addressed by collective action $[25,26]$. Overall mobilization related "pull factors" have played a greater role in bringing MSM towards organized public participation, as compared to vulnerability-related "push factors," thus underlining the importance of community mobilization interventions which was proven as an effective intervention strategy in Indian settings [1].

This study highlights the specific nature of MSMs' "public participation", which indicates their level of empowerment efforts against structural barriers. A study by Tedrow et al. [27] highlighted that while few aspects of community mobilization are more quantifiable others measure intangible, such as the extent to which communities accepted the intervention and the level of diffusion. The study also recommends for a comprehensive measurement tool for community mobilization which should consider "discrete process outcomes as well as the more complex nuances of the mobilization" [27] . In this back ground, the measure of MSMs' "public participation" identified in this study could serve as a new and valid measure reflecting a crucial stage of their community mobilization process. MSM public participation measure would lead to better tracking of the mobilized status of hidden population which needs to be further assessed based on the preliminary findings of this study, in the context of addressing "structural changes" without which HIV prevention remains unfulfilled.

The limitation of this study is that it is cross sectional in design which could not capture the dynamic and lengthy process like community mobilization. The study itself had limited variables to completely represent all crucial stages of community mobilization (like collective efficacy were not covered in this study) and the further assessment of its relation with public participation was not possible. Also due to the small sample size we were limited from doing sub analysis based on self identity of MSM.

\section{Conclusion}

MSM "participation in public spaces" which is also noted as "public visibility of sex workers" quantifies a critical step in the community mobilization process, which has the potential to evolve strongly over time. It symbolizes the passage of MSM community from their individual issues of disease and safety towards broader societal issues and engages with structural barriers.

\section{Acknowledgements}

This paper was written as part of the Knowledge Network project of the Population Council, which is a grantee of the Bill \& Melinda Gates Foundation through Avahan, its India AIDS Initiative. The views expressed herein are those of the authors and do not necessarily reflect the official policy or position of the Bill \& Melinda Gates Foundation and Avahan. We acknowledge Indian Council of Medical Research for its continuous support.

\section{References}

1. AVAHAN (2008) The India AIDS Initiative: The Business of HIV Prevention at Scale.
2. Laurnece $J$ (2007) Men who have sex with men: a new focus internationally. AIDS Read 17: 379-380

3. NACO (2013) Annual Report 2012-13

4. Thomas B, Mimiaga MJ, Kumar S, Swaminathan S, Safren SA, et al. (2011) HIV in Indian MSM: reasons for a concentrated epidemic \& strategies for prevention. Indian J Med Res 134: 920-929.

5. Brahmam GN, Kodavalla V, Rajkumar H, Rachakulla HK, Kallam S, et al (2008) Sexual practices, HIV and sexually transmitted infections among selfidentified men who have sex with men in four high HIV prevalence states of India. AIDS 22 Suppl 5: S45-57.

6. Go VF, Srikrishnan AK, Sivaram S, Murugavel GK, Galai N, et al. (2004) High HIV prevalence and risk behaviors in men who have sex with men in Chennai, India. J Acquir Immune Defic Syndr 35: 314-319.

7. Khan S (2001) Culture, sexualities, and identities: men who have sex with men in India. J Homosex 40: 99-115.

8. WHO (2009) Health Sector Response to HIVIAIDS among MSM: Report of the Consultation.

9. Beattie TS, Bhattacharjee P, Suresh M, Isac S, Ramesh BM, et al. (2012) Personal, interpersonal and structural challenges to accessing HIV testing, treatment and care services among female sex workers, men who have sex with men and transgenders in Karnataka state, South India. J Epidemio Community Health 66 Suppl 2: ii42-48.

10. NACO (2007a) Operational Guidelines for Integrated Counselling and Testing Centres.

11. Blankenship KM, Burroway R, Reed E (2010) Factors associated with awareness and utilisation of a community mobilisation intervention for female sex workers in Andhra Pradesh, India. Sex Transm Infect 86 Suppl 1: i69-75.

12. Gaikwad SS, Bhende A, Nidhi G, Saggurti N, Ranebennur V (2012) How effective is community mobilisation in HIV prevention among highly diverse sex workers in urban settings? The Aastha intervention experience in Mumbai and Thane districts, India. J Epidemiol Community Health 66 Suppl 2: ii69-77.

13. Saggurti N, Mishra RM, Proddutoor L, Tucker S, Kovvali D, et al. (2013) Community collectivization and its association with consistent condom use and STI treatment-seeking behaviors among female sex workers and high-risk men who have sex with men/transgenders in Andhra Pradesh, India. AIDS Care 25 Suppl 1: S55-66.

14. Karikalan N, Seema Sahay, Mandar K Mainkar, Sucheta Deshpande, Sowmya Ramesh, et al. (2014) Female sex worker's participation in the community mobilization process: two distinct forms of participations and associated contextual factors. BMC Public Health 14: 1323.

15. Saidel T, Adhikary R, Mainkar M, Dale J, Loo V, et al. (2008) Baseline integrated behavioural and biological assessment among most at-risk populations in six high-prevalence states of India: design and implementation challenges. AIDS 22 Suppl 5: S17-34.

16. Flora E (2004) Constructing an actionable environment: Collective action for HIV prevention among Kolkata sex workers.

17. Nelson NW (1995) Power and participatory development: theory and practice. London Intermediate Technology Publications.

18. Campbell C, Mzaidume Z (2001) Grassroots participation, peer education, and HIV prevention by sex workers in South Africa. Am J Public Health 91: 19781986.

19. Gutierrez JP, McPherson S, Fakoya A, Matheou A, Bertozzi SM (2010) Community-based prevention leads to an increase in condom use and reduction in sexually transmitted infections (STIs) among men who have sex with men (MSM) and female sex workers (FSW): the Frontiers Prevention Project (FPP) evaluation results. BMC Public Health 10: 497.

20. Ramanathan S, Chakrapani V, Ramakrishnan L, Goswami P, Yadav D, et al (2013) Consistent condom use with regular, paying, and casual male partners and associated factors among men who have sex with men in Tamil Nadu, India: findings from an assessment of a large-scale HIV prevention program. BMC Public Health 13: 827.

21. Ghosh S, Maheswari T, DeZoysa C, Chikukwa P, Samuels F, et al (2008) Community mobilisation of key populations critically reduces vulnerability and significantly increases positive outcomes of a STI prevention programme: results from a four-year impact evaluation study in Andhra Pradesh, India. Paper presented at the XVII International AIDS Conference. 
Citation: Nagarajan K, Sahay S, Ganju D, Paranjape RS (2015) Public Participation of Men Who Have Sex with Men in the Context of Community Empowerment in India. J AIDS Clin Res 6: 509. doi:10.4172/2155-6113.1000509

Page 5 of 5

22. NACO (2007b) Targeted interventions under NACP III: Operational guidelines volume I - core high risk groups.

23. Rosenstock IM, Stretcher VJ, Becker M (1994) The Health Belief Model and HIV Risk Behavior Change. Preventing AIDS: 5-24.

24. Paterson HJ (2009) Introduction to Health Belief Model. New Jersy, USA.

25. Biradavolu MR, Burris S, George A, Jena A, Blankenship KM (2009) Can sex workers regulate police? Learning from an HIV prevention project for sex workers in southern India. Soc Sci Med 68: 1541-1547.
26. Punyam S, Pullikalu RS, Mishra RM, Sandri P, Mutupuru BP, et al. (2012) Community advocacy groups as a means to address the social environment of female sex workers: a case study in Andhra Pradesh, India. J Epidemio Community Health 66 Suppl 2: ii87-94.

27. Tedrow VA, Zelaya CE, Kennedy CE, Morin SF, Khumalo-Sakutukwa G, et al. (2012) No "magic bullet": exploring community mobilization strategies used in a multi-site community based randomized controlled trial: Project Accept (HPTN 043). AIDS Behav 16: 1217-1226. 